\title{
NOUVELLE
}

\section{La fée Nanog ou le retour dans les limbes}

Laure Coulombel

> Dès 1961, la possibilité de fusion spontanée entre des cellules de mammifères était connue [1] et, en 1976, la revue Cell décrivait la formation d'hybrides entre des cellules de tératocarcinomes et des thymocytes ou des érythroblastes adultes [2]. À l'époque, la question était celle de l'extinction du potentiel pluripotent par un génome diploïde adulte. Aujourd'hui, elle est inverse : des noyaux somatiques adultes peuvent-ils ré-acquérir un potentiel de cellules pluripotentes de type embryonnaire par leur fusion avec des cellules ES ? L'alternative étant le transfert de noyaux somatiques dans des ovocytes énucléés. L'enjeu est donc scientifique mais aussi «politique». Le groupe d'Austin Smith avait montré en 2002 la faisabilité de cette stratégie chez la souris [3], les hybrides tétraploïdes formés étant dotés de l'éventail des propriétés de cellules $E S$. Des résultats similaires ont été publiés en 2005 avec des cellules humaines [4]. Les hybrides se comportent comme des cellules $\varepsilon S$ et perdent leurs attributs de cellules adultes comme en attestent leur comportement en culture et la reprogrammation génétique des noyaux somatiques, authentifiée par la perte des marqueurs d'inactivation d'un des deux chromosomes $X$ dans les cellules somatiques $X X$, ou l'activation de gènes déterminant le statut pluripotent des cellules $\varepsilon S$ et normalement éteints dans les cellules adultes, ou, plus rarement, la contribution à un tissu après leur injection dans un blastocyste réimplanté ensuite in vivo. Ainsi, très rapidement après leur fusion, les noyaux somatiques activent le promoteur $0 c t-4$ qui contrôle l'expression d'un gène indicateur (GFP ou résistance à un antibiotique). Ce même groupe d'Austin Smith révèle dans Nature le rôle primordial (mais pas suffisant) de la protéine Nanog dans ce processus de reprogrammation des noyaux somatiques adultes [5]. Nanog est, avec 0ct-4 et Sox2, I'une des trois protéines assurant le maintien épigénétique de l'état pluripotent des cellules $\varepsilon S$, par une orchestration subtile de répresseurs $(\rightarrow)$.

$(\rightarrow) \mathrm{m} / \mathrm{s} 2003, n^{\circ}$ 8-9, p. 798

Trois éléments semblent essentiels à la reprogrammation «embryonnaire » des noyaux somatiques dans les hétérocaryons : en premier lieu, la concentration de la protéine Nanog dans la cellule $\varepsilon S$. Le nombre d'hétérocaryons viables est très augmenté si l'on utilise des cellules ES surexprimant Nanog, mais Nanog n'est cependant pas suffisante pour reprogrammer à elle seule une cellule somatique, et le contexte cellulaire de la cellule $E S$ est requis. Les deux autres paramètres concernent le cycle cellulaire et le statut ontogénique de la cellule somatique utilisée comme partenaire de fusion: les cellules de neurosphères, proliférant activement, sont plus efficaces que les thymocytes, eux-mêmes supérieurs aux fibroblastes. On constate les mêmes différences dans l'efficacité de la reprogrammation après transfert de ces noyaux somatiques dans des ovocytes. Lorsqu'on éteint Nanog (élimination de la cassette Nanog-lox par cre), les hybrides enclenchent un processus de différenciation dans les lignées mésodermiques, endodermiques et ectodermiques, comme le font des cellules ES sevrées de leur milieu d'amplification. Une fusion réussie reste
Inserm U602, Hôpital Paul Brousse, 12, avenue Paul Vaillant Couturier, 94817 Villejuif Cedex, France. laure.coulombel@wanadoo.fr

cependant un événement rare et, pour de multiples raisons, $96 \%$ des hétérocaryons formés (fréquence de $1 \times 10^{-5}$ ou $1 \times 10^{-4}$ ) ne survivent pas. Le défi est maintenant de trouver quelle combinaison de molécules peut reprogrammer une cellule somatique sans la contrainte d'une étape d'hétérocaryon tétraploïde, instable et sans avenir thérapeutique. Duel américano-Japonais? Une équipe japonaise a récemment montré (congrès ISCS, Toronto, Canada $^{1}$ ) que la transfection de quatre ADNc dans des kératinocytes murins adultes leur conférait toutes les propriétés de cellules ES [6]... Ils ont donné trois noms, 0 ct4, Sox2, Myc, gardant secret celui du quatrième larron, mais il est peu probable que ce soit Nanog. Les paris sont lancés... $\diamond$

Nanog and the magic wand

\section{RÉFÉRENCES}

1. Sorieul S, Ephrussi, B. Karyological demonstration of hybridization of mammalian cells in vitro. Nature $1961 ; 190: 653-4$.

2. Miller RA, Ruddle F. Pluripotent teratocarcinomathymus somatic cell hybrids. Cell $1976 ; 9:$ : 45-55.

3. Ying QL, Nichols J, Evans EP, Smith AG. Changing potency by spontaneous fusion. Nature 2002 ; $416: 545-8$.

4. Cowan CA, Atienza J, Melton DA, Eggan K. Nuclear reprogramming of somatic cells after fusion with human embryonic stem cells. Science 2005 ; 309: 1369-73.

5. Silva J, Chambers I, Pollard S, Smith A. Nanog promotes transfer of pluripotency after cell fusion. Nature 2006 ; 441 : 997-1001.

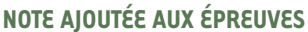

Le suspense vient d'être levé dans Cell... voir Brèves «Des cellules en état de crise identitaire... », page 835 de ce numéro.

${ }^{1}$ International Stem Cell Society, juin 2006. 